\title{
Molecular typing and epidemiology of enteroviruses in Cyprus, 2003-2007
}

\author{
Christina Tryfonos, ${ }^{1}$ Jan Richter, ${ }^{1}$ Dana Koptides, ${ }^{1}$ Minas Yiangou $^{2}$ \\ and Christina G. Christodoulou ${ }^{1}$ \\ ${ }^{1}$ Department of Molecular Virology, Cyprus Institute of Neurology and Genetics, PO Box 23462, \\ 1683 Nicosia, Cyprus \\ ${ }^{2}$ Department of Genetics, Development and Molecular Biology, School of Biology, Aristotle \\ University of Thessaloniki, Thessaloniki, Greece
}

\begin{abstract}
Human enteroviruses (HEVs) are responsible for a wide spectrum of clinical diseases. Even though usually associated with non-specific febrile illness, they are the most common cause of viral meningitis and pose a serious public-health problem, especially during outbreaks. Rapid detection and identification of HEV serotypes in clinical specimens are important in appropriate patient management and epidemiological investigation. A 5 year study (2003-2007) of clinical specimens from patients with viral meningitis and/or symptoms of enteroviral infection was carried out in Cyprus to determine the underlying enteroviral aetiology. Reverse transcription, followed by a sequential PCR strategy targeting the 5' non-coding region and VP1 region, was used for typing the isolated enteroviruses. The serotype of each isolate was determined by BLAST search of the VP1 amplicon sequence against GenBank. Clinical specimens from a total of 146 patients were diagnosed as enterovirus-positive. Twenty-two different serotypes were identified. The main strains identified were echovirus 18 and echovirus 30 , followed by coxsackievirus B5, echovirus 9 , echovirus 6, coxsackievirus A10 and coxsackievirus B2. However, rapid changes in serotype frequency and diversity were observed over time. Serotype distribution corresponded essentially with observations reported from other European countries in the same period. The present report demonstrates the epidemiology of enteroviruses in Cyprus from 2003 to 2007.
\end{abstract}

Received 3 January 2011
Accepted 12 May 2011

\section{INTRODUCTION}

The genus Enterovirus belongs to the family Picornaviridae and currently contains ten species, seven of which include viruses that commonly infect humans (http://www. picornaviridae.com). Human enterovirus (HEV) serotypes were recently reclassified into four groups (A-D), which include echovirus (E), coxsackievirus (CV) A and B, poliovirus (PV) and numbered enteroviruses (EVs) (Brown et al., 2003; Pallansch \& Oberste, 2003; Pallansch \& Roos, 2001; Stanway et al., 2005). HEVs are positive-sense, singlestranded RNA viruses that are transmitted faecal-orally and infect millions of people worldwide each year, with a seasonal peak in summer and autumn in temperate climates. Most infections are asymptomatic or result only in mild illness (such as non-specific febrile illness or mild upper respiratory symptoms). However, HEVs are a common aetiological agent in encephalitis, acute haemorrhagic conjunctivitis, undifferentiated rash, acute flaccid paralysis, myocarditis and neonatal sepsis-like diseases

Abbreviations: CSF, cerebrospinal fluid; CV, coxsackievirus; E, echovirus; EV, enterovirus; HEV, human enterovirus; NC, non-coding; NPEV, non-polio enterovirus; $\mathrm{PV}$, poliovirus.
(Pallansch \& Roos, 2001). The most common of the potentially severe illnesses associated with EV infections, especially in paediatric patients, is aseptic meningitis, which often appears in the form of outbreaks. Non-polio enteroviruses (NPEV) are responsible for $85-95 \%$ of all cases of aseptic meningitis with an identified aetiological agent (Rotbart, 1995).

HEVs are distributed, within a given geographical area, with two major patterns of infection: endemic and epidemic (Pallansch \& Oberste, 2003). This circulation of EVs and the periodic introduction of certain serotypes increase the possibility for the creation of new variants as a result of intratypic and intertypic recombination (McWilliam Leitch et al., 2010; Simmonds \& Welch, 2006). Recombination events have a significant role in the evolution and genetic variability of EVs (Santti et al., 1999). Nevertheless, the genetic variability of EVs is caused mostly by the high mutation rate that generally characterizes RNA viruses, due to the lack of proofreading activity of the viral RNA-dependent RNA polymerase during genome replication (Drake \& Holland, 1999).

Nowadays, there are numerous antigenically distinct serotypes because of these genetic-variation mechanisms. 
Therefore, the laboratory detection of EVs can no longer be based on serotyping procedures, due to the necessity for corresponding antibodies for recognition of the antigenic epitopes. In order to solve the problems of limited existence of type-specific antisera and cross-reactivity, cell-culture and molecular (such as PCR) assays are being used (Bolanaki et al., 2008; Caro et al., 2001; Casas et al., 2001; Iturriza-Gómara et al., 2006; Nix et al., 2006; Oberste et al., 2000, 2003). Molecular methods for the detection of HEVs rely on the fact that the genome of EVs has a highly conserved region in the $5^{\prime}$ non-coding end, which contains the cloverleaf structure and the internal ribosome entry site. The most variable region is the VP1 region, which encodes serotype-specific neutralization epitopes. The hypervariable $\mathrm{BC}$ loop, within the $\mathrm{N}$ terminus of the VP1 protein, has an important role in reactivity with typespecific antibodies. These characteristics of the VP1 region explain why it is widely targeted for typing of EVs (Muir et al., 1998; Norder et al., 2001; Palacios et al., 2002).

This study reports the molecular detection and typing of EVs isolated from clinical specimens from patients diagnosed with aseptic meningitis and other EV infections in Cyprus between 2003 and 2007.

\section{METHODS}

Patients and clinical samples. Between January 2003 and December 2007, our laboratory tested clinical specimens obtained from 246 hospitalized patients, from all Governmental Hospitals of Cyprus and from private clinics, with suspected viral meningitis or EV infection manifestations. The clinical samples were cerebrospinal fluid (CSF), pharyngeal swabs, blood samples and/or stool samples. Patients' ages ranged from newborn to 67 years, with $>97 \%$ of patients being $<15$ years old. Children under 1 year accounted for $40 \%$ of patients of known age, followed by the groups of patients aged $1-5$ years $(32 \%)$ and $6-10$ years (18\%). In 2003 and from January to November 2004, clinical specimens were tested routinely in the laboratory by an in-house nested RT-PCR assay targeting a sequence in the highly conserved $5^{\prime} \mathrm{NC}$ region as described previously (Richter et al., 2006). From December 2004, an in-house two-step real-time RT-PCR assay was employed for routine laboratory diagnosis of EVs. The molecular diagnostic analysis was positive for 146 of 246 patients. Ninety-one of 173 CSF samples (53\%), 76 of 102 stool samples $(75 \%)$ and five of five pharyngeal swabs (100\%) were found to be EV-positive.

Extraction and real-time RT-PCR. Stool samples were treated as described by the WHO (2003). Viral RNA was extracted from $150 \mu \mathrm{l}$ clinical specimen by using a QIAamp Viral RNA Mini kit (Qiagen) according to the manufacturer's instructions. Real-time PCR for the detection of EV was performed as a two-step assay (separate reverse transcription followed by real-time PCR). For reverse transcription, $0.8 \mu \mathrm{l}$ primer HEV $7(25 \mu \mathrm{M})$ (Table 1$), 0.8 \mu \mathrm{l} 25 \mathrm{mM}$ dNTP mix and $4.5 \mu \mathrm{l} \mathrm{H}_{2} \mathrm{O}$ were added to $10 \mu \mathrm{l}$ RNA. The mixture was heated to $95{ }^{\circ} \mathrm{C}$ for $5 \mathrm{~min}$ and subsequently snap-cooled on ice for $1 \mathrm{~min}$. To each sample was added $3.9 \mu \mathrm{l}$ of a reaction mixture containing $10 \mathrm{mM}$ Tris/HCl (pH 8.3), $50 \mathrm{mM} \mathrm{KCl,} 3 \mathrm{mM} \mathrm{MgCl}$, $20 \mathrm{U}$ RNase inhibitor and $30 \mathrm{U}$ SuperScript III reverse transcriptase (Invitrogen). cDNA synthesis was performed for $30 \mathrm{~min}$ at $42{ }^{\circ} \mathrm{C}$. cDNA product $(7.5 \mu \mathrm{l})$ was added to $30 \mu \mathrm{l}$ of a real-time PCR mixture containing $1 \times$ Universal TaqMan Mix (Applied Biosystems), $0.2 \mu \mathrm{M}$ probe, $0.3 \mu \mathrm{M}$
Table 1. Oligonucleotide primers used for RT-PCR and the VP1 PCR

\begin{tabular}{|llc|}
\hline Primer & \multicolumn{1}{c|}{ Sequence $\left(\mathbf{5}^{\prime} \rightarrow \mathbf{3}^{\prime}\right)$} & Position $^{*}$ \\
\hline Forward primers & & \\
292B & ACIGCIGYIGARACNGG & 2611-2627 \\
292A & CAAGCIGCIGARACNGG & \\
292C & ACIGCIGTIGARACNGG & \\
Reverse primers & & \\
222B & CCICCIGGIGGIAYRTACAT & 2969-2950 \\
222A & GCICCIGGIGGIACRWACAT \\
222C & GCICCTGGIGGIAYRTACAT \\
Reverse transcription & \\
HEV 7 & ATTGTCACCATAAGCAGCCA & $594-575$ \\
HEV 6.1 & CCCTGAATGCGGCTAATCC & $449-467$ \\
EV probe & ACGGACACCCAAAGTAGTC & $555-531$ \\
\multicolumn{3}{c}{ GGTTCC } \\
\hline
\end{tabular}

${ }^{\star}$ Positions of primers are relative to the genome of PV type 1, Mahoney strain (GenBank accession no. V01148).

HEV 7 and $0.15 \mu \mathrm{M}$ HEV 6.1 primers. All reactions were performed in duplicate. Incubation was carried out at $95{ }^{\circ} \mathrm{C}$ for $10 \mathrm{~min}$, followed by 45 cycles of $95{ }^{\circ} \mathrm{C}$ for $15 \mathrm{~s}$ and $60{ }^{\circ} \mathrm{C}$ for $1 \mathrm{~min}$ in an ABI 7500 instrument (Applied Biosystems).

5' NC region nested RT-PCR. As described previously, our typing strategy is based on the sequencing of a large part of the $5^{\prime} \mathrm{NC}$ region and amplification of a part of the VP1 region (Richter et al., 2006). Briefly, an approximately $399 \mathrm{bp}$ fragment of the highly conserved 5' NC region was amplified by an in-house nested RT-PCR. Amplification involved 40 cycles of denaturation at $95{ }^{\circ} \mathrm{C}$ for $30 \mathrm{~s}$, annealing at $42{ }^{\circ} \mathrm{C}$ for $45 \mathrm{~s}$ and elongation at $72{ }^{\circ} \mathrm{C}$ for $1 \mathrm{~min}$. The approximately 399 bp products were visualized in a $1.5 \%$ agarose gel containing $1 \mu \mathrm{g}$ ethidium bromide $\mathrm{ml}^{-1}$.

Amplification of VP1-encoding sequences. The 222/292 primer set has a broad specificity and has been shown to amplify all known EV serotypes successfully, as well as to identify newly emerging serotypes (Oberste et al., 2003). In order to do so, these primers contain several deoxyinosine residues and are highly degenerated, thereby limiting the sensitivity of amplification that can be achieved. It is possible to reduce the degree of degeneration by targeting groups of serotypes with high sequence similarity. Three different primer sets were developed (Table 1). Each of these primer sets is more sensitive and specific for a different group of EV serotypes. For reverse transcription, $2 \mu \mathrm{l}$ random hexamers (15 $\mu \mathrm{M}$; Invitrogen) and $8 \mu \mathrm{l}$ of a $2.5 \mathrm{mM}$ dNTP mix were added to $5 \mu \mathrm{l} \mathrm{RNA}$. The mixture was heated to $95{ }^{\circ} \mathrm{C}$ for $5 \mathrm{~min}$ and subsequently snapcooled on ice for $1 \mathrm{~min}$. To each sample was added $5 \mu \mathrm{l}$ of a reaction mixture containing $10 \mathrm{mM}$ Tris/ $\mathrm{HCl}(\mathrm{pH} 8.3), 50 \mathrm{mM} \mathrm{KCl}, 3 \mathrm{mM}$ $\mathrm{MgCl}_{2}, 20 \mathrm{U}$ RNase inhibitor and $30 \mathrm{U}$ SuperScript III reverse transcriptase (Invitrogen). cDNA synthesis was performed at $25^{\circ} \mathrm{C}$ for $10 \mathrm{~min}$ and at $42{ }^{\circ} \mathrm{C}$ for $45 \mathrm{~min}$. Five microlitres of cDNA product was added to $35 \mu$ l of a PCR mixture containing a final concentration of $10 \mathrm{mM}$ Tris/ $\mathrm{HCl}(\mathrm{pH} 8.3), 50 \mathrm{mM} \mathrm{KCl}, 1.5 \mathrm{mM}$ $\mathrm{MgCl}_{2}, 0.4 \mathrm{mM}$ dNTPs, $0.5 \mu \mathrm{M}$ of each primer (forward and reverse) and $2 \mathrm{U}$ AmpliTaq Gold DNA polymerase (Applied Biosystems). Amplification and visualization by agarose gel electrophoresis were performed as described above; the amplicons were approximately $357 \mathrm{bp}$ long. 
Sequencing. Amplicons were purified by using a Montage DNA Gel Extraction kit (Millipore) and sequenced on a CEQ 8000 sequencer (Beckman Coulter) in the forward and reverse directions, using the respective PCR primers and a CEQ Dye Terminator Cycle Sequencing with Quick Start kit (Beckman Coulter). The sequencing results were used for a BLAST search against GenBank.

Phylogenetic analysis. Phylogenetic analyses were conducted by using MEGA4 (Tamura et al., 2007). Phylogenetic trees were inferred by using the neighbour-joining method. Evolutionary distances were computed by using the $p$-distance method and are in units of the number of amino acid differences per site. The bootstrap consensus tree inferred from 1000 replicates is taken to represent the evolutionary history of the taxa analysed. All ambiguous positions were removed for each sequence pair. For reasons of clarity, interior branches representing distinct clusters were collapsed into elongated triangles, whose thickness is proportional to the number of taxa condensed and whose width is proportional to the maximum distance between taxa.

\section{RESULTS}

Over the 5 year period, EV RNA was detected in 228 clinical specimens obtained from 146 patients with suspected viral meningitis or manifestations of EV infection. One hundred and forty-six CSF, pharyngeal swab, blood and/or stool samples were analysed for epidemiological surveillance. In several cases, more than one specimen - e.g. CSF and stools - from a patient were used for typing. As the typing results were identical, for the purpose of simplicity, in the following results, the number of samples refers to the number of patients. A nested RTPCR was employed to amplify part of the highly conserved $5^{\prime} \mathrm{NC}$ region. The sequences obtained were compared with those available in GenBank. Of the 146 samples, 141 were NPEVs belonging to species HEV-A and HEV-B, three were PVs and two corresponded to rhinoviruses. The three PVs were analysed further by sequencing of additional fragments in order to differentiate between the Sabin and wild-type strains (Richter et al., 2008). All were identified to be Sabin-like PVs. One was type 3 Sabin PV and the other two were type 1 and type 2 .

A phylogenetic tree was constructed from the aligned NPEV partial $5^{\prime} \mathrm{NC}$ region sequences and homologous sequences from GenBank, in order to guide the choice of the set of primer pairs for the VP1 RT-PCR (tree available on request). All of the VP1 sequences obtained were used as query sequences for comparison with those included in GenBank and each sample was assigned the serotype that gave the highest identity score, regarding the sequence similarity criteria defined by Oberste et al. (1999). A phylogenetic tree was constructed on the basis of an amino acid alignment of all VP1 fragments, including relevant reference strains from GenBank, by using the neighbourjoining method. In the VP1 tree (Fig. 1), clinical specimens of the same serotype clustered together with the respective GenBank reference sequences, further confirming the serotype identification and supported by high bootstrap values. All samples formed monophyletic clusters with the

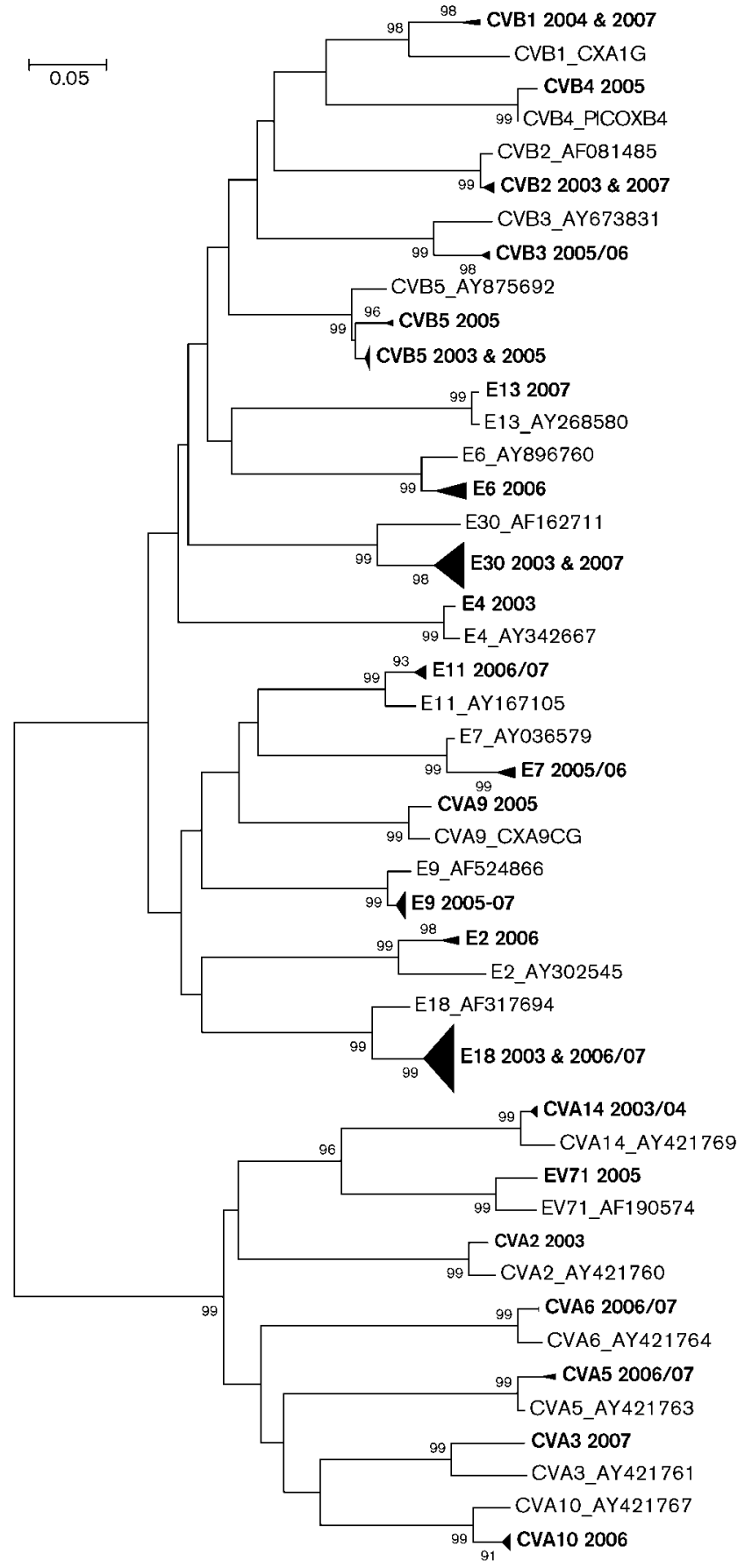

Fig. 1. Phylogenetic tree based on partial VP1 sequences obtained from clinical specimens from patients with EV infection in Cyprus from 2003 to 2007 and reference sequences available in GenBank. All clinical isolates clustered with their respective reference stains with $99 \%$ bootstrap values. Clinical samples are indicated in bold.

exception of CVB5, where two distinct lineages were observed. Unambiguous identification was achieved for 134 patients. A total of seven EV-positive specimens remained unidentified, either because the viral load was 
too low, even after cell culture (unculturable serotype), or because the amount of sample was limited.

The distribution of the NPEV serotypes identified in Cyprus from 2003 to 2007 is shown in Table 2. Twenty-two different EV serotypes were identified. E18 and E30 were the most frequently isolated serotypes, followed by CVB5, E9, E6, CVA10 and CVB2. E7, E11, CVA14, CVA5 and CVB3 were detected sporadically. Serotypes CVB1 and CVA6 were each identified twice, while E13, E4, EV71, CVB4, CVA9, E2, CVA2 and CVA3 were each detected only once.

The number of EV-positive specimens varied throughout a single year and also between years. Every year, a low period of incidence was observed during winter and a high period from March to November, with a peak in summer and autumn. In 2007, a second peak was observed in December caused by E30. The overall NPEV-detection rate was highest in 2006 (39\%) and 2007 (32\%), with E18 (35\%) and E30 (52\%) being the most prevalent serotypes. 2004 was characterized by very low EV detection. In summer 2005, CVB5 (55\%) was the most frequently isolated serotype, followed by E9 (20\%) in autumn and winter. E9 was isolated until May 2006, when E6 appeared. In summer 2006, CVA10 was identified most frequently. E6 became predominant in September 2006, but its incidence declined rapidly in the following months as it was superseded by E18, which dominated until May 2007, when E30 became the most prevalent serotype. E30 peaked in August 2007 and continued to dominate until December 2007, when it gave rise to a second bigger peak.

\section{DISCUSSION}

Worldwide, HEVs are responsible for a wide spectrum of clinical diseases. Even though usually associated with nonspecific febrile illness, they can also cause severe infections and thus pose a serious public-health problem, especially during outbreaks. Rapid HEV detection and subsequent identification of the serotype in clinical cases is important for monitoring emergence and spread of more pathogenic variants, for epidemiological surveillance and for distinguishing between PVs and NPEVs (Antona et al., 2007; Archimbaud et al., 2009; Cabrerizo et al., 2008; Mirand et al., 2006). The genetic diversity of EVs makes it difficult to develop a molecular typing assay that is both sensitive and easy to perform (Leitch et al., 2009; Nix et al., 2006; Tavakoli et al., 2008). However, many molecular methods have been developed for the typing of HEVs, most of them targeting the VP1 region. Data obtained by partial sequencing of the $5^{\prime} \mathrm{NC}$ region were used for distinguishing PVs from NPEVs (Hyypiä et al., 1997; Thoelen et al., 2004) and for guiding the choice of primers for the VP1 RT-PCR. Our typing approach, as described by Richter et al. (2006), became less laborious and turnaround time was reduced by employing the 222/292 primer set of Oberste et al. (2003). Furthermore, we were able to identify

Table 2. EV serotypes identified from 141 patients with EV infection in Cyprus from 2003 to 2007

\begin{tabular}{|c|c|c|c|c|c|c|}
\hline & 2003 & 2004 & 2005 & 2006 & 2007 & Total \\
\hline CVB1 & 0 & 1 & 0 & 0 & 1 & 2 \\
\hline CVB2 & 4 & 0 & 0 & 0 & 2 & 6 \\
\hline CVB3 & 0 & 0 & 1 & 2 & 0 & 3 \\
\hline CVB4 & 0 & 0 & 1 & 0 & 0 & 1 \\
\hline CVB5 & 1 & 0 & 11 & 0 & 0 & 12 \\
\hline E2 & 0 & 0 & 0 & 3 & 0 & 3 \\
\hline E4 & 1 & 0 & 0 & 0 & 0 & 1 \\
\hline E6 & 0 & 0 & 0 & 8 & 0 & 8 \\
\hline E7 & 0 & 0 & 1 & 4 & 0 & 5 \\
\hline E9 & 0 & 0 & 4 & 5 & 2 & 11 \\
\hline E11 & 0 & 0 & 0 & 1 & 4 & 5 \\
\hline E13 & 0 & 0 & 0 & 0 & 1 & 1 \\
\hline E18 & 3 & 0 & 0 & 20 & 8 & 31 \\
\hline E30 & 1 & 0 & 0 & 0 & 24 & 25 \\
\hline CVA2 & 1 & 0 & 0 & 0 & 0 & 1 \\
\hline CVA3 & 0 & 0 & 0 & 0 & 1 & 1 \\
\hline CVA5 & 0 & 0 & 0 & 2 & 1 & 3 \\
\hline CVA6 & 0 & 0 & 0 & 1 & 1 & 2 \\
\hline CVA9 & 0 & 0 & 1 & 0 & 0 & 1 \\
\hline CVA10 & 0 & 0 & 0 & 6 & 0 & 6 \\
\hline CVA14 & 3 & 2 & 0 & 0 & 0 & 5 \\
\hline EV71 & 0 & 0 & 1 & 0 & 0 & 1 \\
\hline Untyped & 1 & 0 & 0 & 5 & 1 & 7 \\
\hline Total & 15 & 3 & 20 & 57 & 46 & 141 \\
\hline
\end{tabular}


a broader range of serotypes in clinical specimens, particularly rare or new serotypes. Because of the typically low viral loads in clinical samples (e.g. serum or CSF), an effort was made to reduce the degree of degeneration in primers 222 and 292, in order to increase the sensitivity of the assay. For this purpose, the 222/292 primer set was used as template for the development of three slightly modified primer sets (Table 1). Each of these primer sets is designed to match one specific HEV species (A, B or C) and offers a higher sensitivity with regard to this HEV species (data not shown). This approach proved especially useful for HEVs of group A, which are difficult to grow in cell culture and therefore typing must be performed using the original, usually low-concentration, sample. Employing this primer set to human HEV-B was also advantageous, as labourintensive cell culturing could often be avoided.

In this study, EVs isolated from clinical specimens from 146 patients with EV-infection manifestations were analysed. The majority of the EV-positive isolates originated from hospitalized patients diagnosed with acute viral meningitis $(63 \%)$. In addition, 18 patients $(12 \%)$ suffered from gastroenteritis. For the rest of the patients, the reported main symptoms were fever, headache, rash and skin lesions (haemorrhagic exanthema; hand, foot and mouth disease). Fig. 2 shows the relationship between clinical symptoms and the serotypes of EV identified; in Fig. 3, the age distribution of the patients according to serotypes identified is shown. The majority of patients were $<15$ years of age. Serotypes E18 and E30, which caused outbreaks, were identified more frequently in children aged between 2 and 10 years old. Children under 1 year of age were more susceptible to sporadic infections by a wider range of different serotypes.

Although the samples originated from all governmental hospitals and private clinics in Cyprus, the two cities with the largest populations made up $>76 \%$ of the isolates. The highest incidence of EV infections was observed in Nicosia (39\%), followed by Limassol (37\%). Nicosia is the capital of Cyprus and the biggest city on the mainland. Limassol is a coastal city and the second largest, welcoming the majority of tourists.

The most frequently identified NPEV serotypes were E18 $(22.0 \%)$ and E30 (17.7\%), followed by CVB5 (8.5\%), E9 (7.8\%), E6 (5.7\%), CVA10 (4.3\%) and CVB2 (4.3\%). It seems that these serotypes caused temporally separated outbreaks that succeeded each other. These findings are in accordance with other epidemiological studies, where predominant serotypes and ranking of individual EVs changed over time, as epidemics occurred (Antona et al., 2007; Bahri et al., 2005; CDC, 2003, 2006; Khetsuriani et al., 2006a, b; Roth et al., 2007; Trallero et al., 2010; Tsao et al., 2010). E18 emerged in Cyprus in 2003, causing sporadic cases before it became the predominant serotype in autumn of 2006 lasting until spring 2007. This trend was also reported in other EVsurveillance studies. While E18 was among the most frequent serotypes isolated in Europe and the USA after 2000 (Khetsuriani et al., 2006b; Thoelen et al., 2003), it seems that its incidence increased in 2005-2006 (Antona et al., 2005; Mirand et al., 2006; Roth et al., 2007; Tavakoli et al., 2008). The second most common serotype detected was E30. It was the causative serotype of the aseptic meningitis outbreak in Cyprus in epidemic years 2000-2001 (Richter et al., 2006). As E30 has been prominent in meningitis outbreaks in France (2000 and 2005) (Antona et al., 2005, 2007; Brunel et al., 2008; Mirand et al., 2006, 2008), Spain (1998, 2000, 2002, 2006 and 2007) (Cabrerizo et al., 2008; Trallero et al., 2010), Germany (2000-2001 and 2005-2006) (Roth et al., 2007), Kosovo and Latvia (2006) (Eurosurveillance Weekly, 2006; Perevoscikovs et al., 2006), Belgium and Austria (2000) (Ortner et al., 2009; Thoelen et al., 2003), its epidemiological status has been studied extensively (Bailly et al., 2009; Kapusinszky et al.,

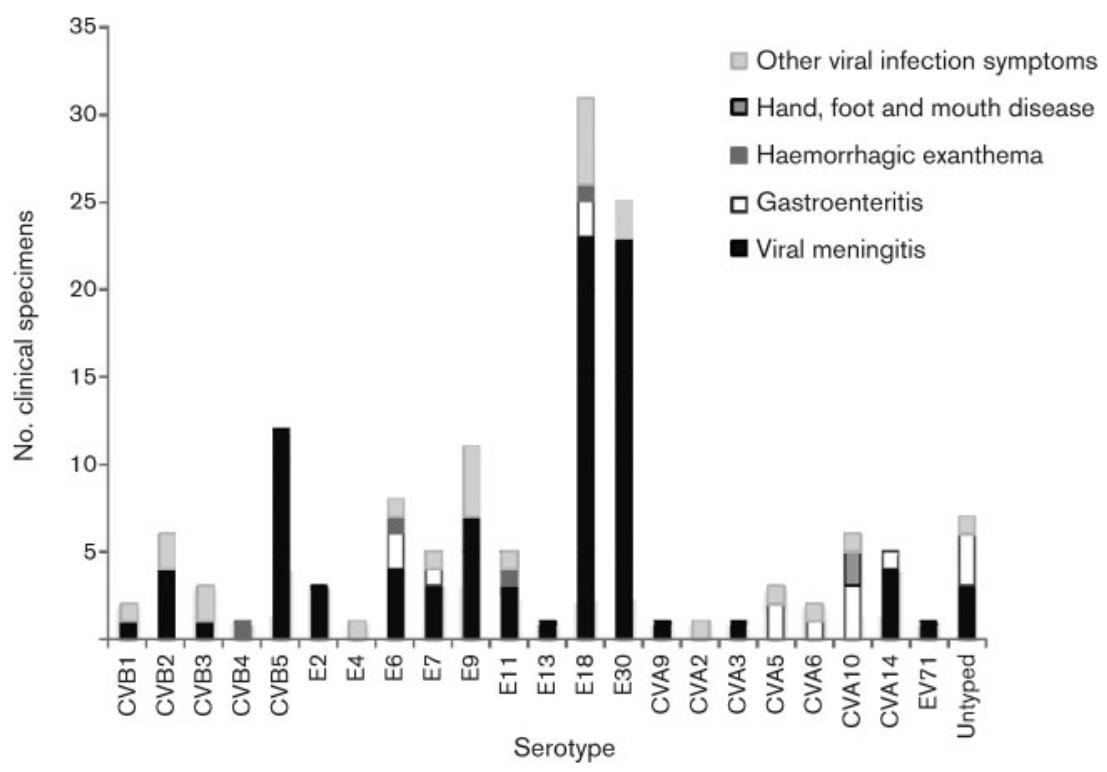

Fig. 2. Relationship between clinical symptoms and the serotype of EVs identified. The main clinical syndrome was viral meningitis. Serotypes E18, E30 and CVB5 were the most frequently detected in clinical specimens from patients with viral meningitis. Unspecific symptoms such as fever, headache, rash and diarrhoea have been included in 'other viral infection symptoms'. 


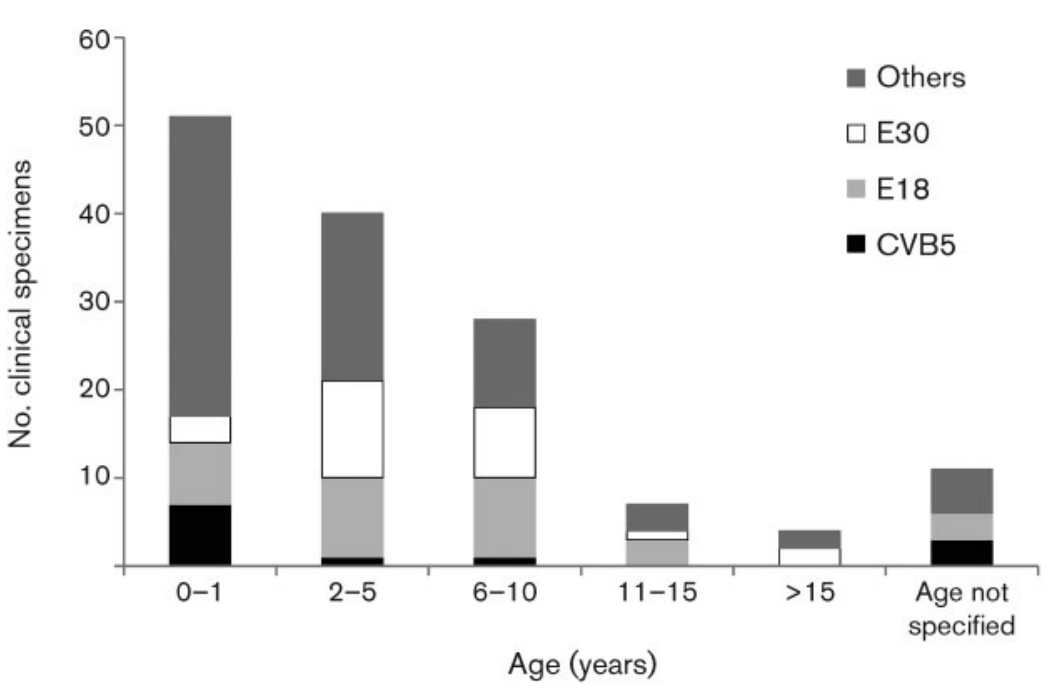

Fig. 3. Age distribution of patients according to serotypes identified. The three most frequently detected serotypes (E18, E30 and CVB5), in clinical specimens from patients with viral meningitis, are shown separately.
2010; Lévêque et al., 2010; Lukashev et al., 2008; McWilliam Leitch et al., 2009, 2010; Mirand et al., 2007). It has been suggested that E30 does not seem to be restricted geographically, but that a particular genotype circulates in different regions of the world simultaneously (Cabrerizo et al., 2008). In addition, it has been reported that this serotype follows an epidemic mode of transmission, causing large outbreaks followed by periods of quiescence (Mirand et al., 2007; Tavakoli et al., 2008; Thoelen et al., 2003). The incidences of E30 in Cyprus seem to follow this pattern. Whilst CVB5, E6 and E9 are among the most common serotypes reported in EV-surveillance studies (Bahri et al., 2005; Cabrerizo et al., 2008; CDC, 2003; Kapusinszky et al., 2010; Khetsuriani et al., 2006b; Mirand et al., 2008; Tavakoli et al., 2008; Trallero et al., 2010), CVA10 is rarely reported. This difference may be attributed in part to the fact that CVA10 was isolated from throat swabs and stool specimens from patients with skin lesion diseases (haemorrhagic exanthema; hand, foot and mouth disease) or gastroenteritis, whereas acute meningitis is the main syndrome studied, especially in European countries. EV isolation from CSF collected from patients with neurological diseases has high significance. In contrast, the presence of EV in stools does not provide evidence of aetiology, as virus shedding may occur asymptomatically and for a long period of time.

EVs demonstrate a marked seasonality in temperate climates, with a typical EV season occurring during JuneOctober (Antona et al., 2007; CDC, 2003). Our study showed a seasonal pattern of distribution, with the incidence of EV infections peaking in summer and autumn. In 2007, which can be characterized as an epidemic year, a second peak was observed in winter. This peak was caused by E30 and was higher than during the summer. Even though winter outbreaks of EVs are rarely reported (Antona et al., 2007; Chambon et al., 2001), in Cyprus they have been reported previously (Richter et al., 2006) and are probably associated with persisting mild temperatures.

In general, the pattern of HEV serotypes circulating in Europe is similar to the pattern of serotypes observed in
Cyprus each year. HEVs have no known non-human host or reservoir, so their circulation is linked to host mobility (Morens \& Pallansch, 1995). Even though Cyprus is an island, the large number of tourists (approx. 2 million) arriving each year in Cyprus, compared with the small population (approx. 800000 ), is probably a major factor in the epidemiology of EVs in Cyprus.

No wild-type PV strain was detected during the 5 years of surveillance, although three Sabin-like PVs (vaccine strains) were detected. The last case of wild-type PV in Cyprus occurred in 1995 (Richter et al., 2008). Since then, Cyprus belongs to the countries considered PV-free by the WHO.

In conclusion, this study covered five EV seasons, which, combined with the three seasons covered by Richter et al. (2006), comprise a total of 8 years surveillance of EV circulation in Cyprus. We observed a serotype distribution that corresponded largely to observations in other European countries during the same period. Molecular typing of EVs, along with the clinical severity associated with each serotype, will provide real-time warning for outbreaks and epidemics.

\section{ACKNOWLEDGEMENTS}

This study was supported financially by the Cyprus Research Foundation (grant PENEK/ENISX/0308/25), the Structural Funds of EU in Cyprus and European Fund of Regional Growth of EU, the Cyprus Institute of Neurology and Genetics and the Cyprus Ministry of Health.

\section{REFERENCES}

Antona, D., Chomel, J. J. with the Enterovirus Surveillance Laboratory Network (2005). Increase in viral meningitis cases reported in France, summer 2005. Euro Surveill 10, E050908, 1.

Antona, D., Lévêque, N., Chomel, J. J., Dubrou, S., Lévy-Bruhl, D. \& Lina, B. (2007). Surveillance of enteroviruses in France, 2000-2004. Eur J Clin Microbiol Infect Dis 26, 403-412. 
Archimbaud, C., Chambon, M., Bailly, J. L., Petit, I., Henquell, C., Mirand, A., Aublet-Cuvelier, B., Ughetto, S., Beytout, J. \& other authors (2009). Impact of rapid enterovirus molecular diagnosis on the management of infants, children, and adults with aseptic meningitis. J Med Virol 81, 42-48.

Bahri, O., Rezig, D., Nejma-Oueslati, B. B., Yahia, A. B., Sassi, J. B., Hogga, N., Sadraoui, A. \& Triki, H. (2005). Enteroviruses in Tunisia: virological surveillance over 12 years (1992-2003). J Med Microbiol 54, 63-69.

Bailly, J. L., Mirand, A., Henquell, C., Archimbaud, C., Chambon, M., Charbonné, F., Traoré, O. \& Peigue-Lafeuille, H. (2009). Phylogeography of circulating populations of human echovirus 30 over 50 years: nucleotide polymorphism and signature of purifying selection in the VP1 capsid protein gene. Infect Genet Evol 9, 699-708.

Bolanaki, E., Kottaridi, C., Dedepsidis, E., Kyriakopoulou, Z., Pliaka, V., Pratti, A., Levidiotou-Stefanou, S. \& Markoulatos, P. (2008). Direct extraction and molecular characterization of enteroviruses genomes from human faecal samples. Mol Cell Probes 22, 156-161.

Brown, B., Oberste, M. S., Maher, K. \& Pallansch, M. A. (2003). Complete genomic sequencing shows that polioviruses and members of human enterovirus species $\mathrm{C}$ are closely related in the noncapsid coding region. J Virol 77, 8973-8984.

Brunel, D., Lévêque, N., Jacques, J., Renois, F., Motte, J. \& Andréoletti, L. (2008). Clinical and virological features of an aseptic meningitis outbreak in North-Eastern France, 2005. J Clin Virol 42, 225-228.

Cabrerizo, M., Echevarria, J. E., González, I., de Miguel, T. \& Trallero, G. (2008). Molecular epidemiological study of HEV-B enteroviruses involved in the increase in meningitis cases occurred in Spain during 2006. J Med Virol 80, 1018-1024.

Caro, V., Guillot, S., Delpeyroux, F. \& Crainic, R. (2001). Molecular strategy for 'serotyping' of human enteroviruses. J Gen Virol 82, 79-91.

Casas, I., Palacios, G. F., Trallero, G., Cisterna, D., Freire, M. C. \& Tenorio, A. (2001). Molecular characterization of human enteroviruses in clinical samples: comparison between VP2, VP1, and RNA polymerase regions using RT nested PCR assays and direct sequencing of products. J Med Virol 65, 138-148.

CDC (2003). Outbreaks of aseptic meningitis associated with echoviruses 9 and 30 and preliminary surveillance reports on enterovirus activity - United States, 2003. MMWR Morb Mortal Wkly Rep 52, 761-764.

CDC (2006). Enterovirus surveillance - United States, 2002-2004. MMWR Morb Mortal Wkly Rep 55, 153-156.

Chambon, M., Archimbaud, C., Bailly, J. L., Henquell, C., Regagnon, C., Charbonné, F. \& Peigue-Lafeuille, H. (2001). Circulation of enteroviruses and persistence of meningitis cases in the winter of 1999-2000. J Med Virol 65, 340-347.

Drake, J. W. \& Holland, J. J. (1999). Mutation rates among RNA viruses. Proc Natl Acad Sci U S A 96, 13910-13913.

Eurosurveillance Weekly (2006). Enteroviral meningitis outbreak, Kosovo, July-September 2006. Euro Surveill 11, E060914, 4.

Hyypiä, T., Hovi, T., Knowles, N. J. \& Stanway, G. (1997). Classification of enteroviruses based on molecular and biological properties. J Gen Virol 78, 1-11.

Iturriza-Gómara, M., Megson, B. \& Gray, J. (2006). Molecular detection and characterization of human enteroviruses directly from clinical samples using RT-PCR and DNA sequencing. J Med Virol 78, 243-253.

Kapusinszky, B., Szomor, K. N., Farkas, A., Takács, M. \& Berencsi, G. (2010). Detection of non-polio enteroviruses in Hungary 2000-2008 and molecular epidemiology of enterovirus 71, coxsackievirus A16, and echovirus 30. Virus Genes 40, 163-173.
Khetsuriani, N., Lamonte, A., Oberste, M. S. \& Pallansch, M. (2006a). Neonatal enterovirus infections reported to the national enterovirus surveillance system in the United States, 1983-2003. Pediatr Infect Dis J 25, 889-893.

Khetsuriani, N., Lamonte-Fowlkes, A., Oberst, S. \& Pallansch, M. A. (2006b). Enterovirus surveillance - United States, 1970-2005. MMWR Surveill Summ 55, 1-20.

Leitch, E. C., Harvala, H., Robertson, I., Ubillos, I., Templeton, K. \& Simmonds, P. (2009). Direct identification of human enterovirus serotypes in cerebrospinal fluid by amplification and sequencing of the VP1 region. J Clin Virol 44, 119-124.

Lévêque, N., Jacques, J., Renois, F., Antona, D., Abely, M., Chomel, J. J. \& Andréoletti, L. (2010). Phylogenetic analysis of echovirus 30 isolated during the 2005 outbreak in France reveals existence of multiple lineages and suggests frequent recombination events. J Clin Virol 48, 137-141.

Lukashev, A. N., Ivanova, O. E., Eremeeva, T. P. \& Gmyl, L. V. (2008). Analysis of echovirus 30 isolates from Russia and new independent states revealing frequent recombination and reemergence of ancient lineages. J Clin Microbiol 46, 665-670.

McWilliam Leitch, E. C., Bendig, J., Cabrerizo, M., Cardosa, J., Hyypiä, T., Ivanova, O. E., Kelly, A., Kroes, A. C., Lukashev, A. \& other authors (2009). Transmission networks and population turnover of echovirus 30. J Virol 83, 2109-2118.

McWilliam Leitch, E. C., Cabrerizo, M., Cardosa, J., Harvala, H., Ivanova, O. E., Kroes, A. C., Lukashev, A., Muir, P., Odoom, J. \& other authors (2010). Evolutionary dynamics and temporal/geographical correlates of recombination in the human enterovirus echovirus types 9, 11, and 30. J Virol 84, 9292-9300.

Mirand, A., Archimbaud, C., Henquell, C., Michel, Y., Chambon, M., Peigue-Lafeuille, H. \& Bailly, J. L. (2006). Prospective identification of HEV-B enteroviruses during the 2005 outbreak. J Med Virol 78, 1624-1634.

Mirand, A., Henquell, C., Archimbaud, C., Peigue-Lafeuille, H. \& Bailly, J. L. (2007). Emergence of recent echovirus 30 lineages is marked by serial genetic recombination events. J Gen Virol 88, 166176.

Mirand, A., Henquell, C., Archimbaud, C., Chambon, M., Charbonne, F., Peigue-Lafeuille, H. \& Bailly, J. L. (2008). Prospective identification of enteroviruses involved in meningitis in 2006 through direct genotyping in cerebrospinal fluid. J Clin Microbiol 46, 87-96.

Morens, D. \& Pallansch, M. A. (1995). Epidemiology. In Human Enterovirus Infections, pp. 3-24. Edited by H. A. Rotbart. Washington, DC: American Society for Microbiology.

Muir, P., Kämmerer, U., Korn, K., Mulders, M. N., Pöyry, T., Weissbrich, B., Kandolf, R., Cleator, G. M., van Loon, A. M. for The European Union Concerted Action on Virus Meningitis and Encephalitis (1998). Molecular typing of enteroviruses: current status and future requirements. Clin Microbiol Rev 11, 202-227.

Nix, W. A., Oberste, M. S. \& Pallansch, M. A. (2006). Sensitive, seminested PCR amplification of VP1 sequences for direct identification of all enterovirus serotypes from original clinical specimens. J Clin Microbiol 44, 2698-2704.

Norder, H., Bjerregaard, L. \& Magnius, L. O. (2001). Homotypic echoviruses share aminoterminal VP1 sequence homology applicable for typing. J Med Virol 63, 35-44.

Oberste, M. S., Maher, K., Kilpatrick, D. R. \& Pallansch, M. A. (1999). Molecular evolution of the human enteroviruses: correlation of serotype with VP1 sequence and application to picornavirus classification. J Virol 73, 1941-1948.

Oberste, M. S., Maher, K., Flemister, M. R., Marchetti, G., Kilpatrick, D. R. \& Pallansch, M. A. (2000). Comparison of classic and molecular 
approaches for the identification of untypeable enteroviruses. J Clin Microbiol 38, 1170-1174.

Oberste, M. S., Nix, W. A., Maher, K. \& Pallansch, M. A. (2003). Improved molecular identification of enteroviruses by RT-PCR and amplicon sequencing. J Clin Virol 26, 375-377.

Ortner, B., Huang, C. W., Schmid, D., Mutz, I., Wewalka, G., Allerberger, F., Yang, J. Y. \& Huemer, H. P. (2009). Epidemiology of enterovirus types causing neurological disease in Austria 19992007: detection of clusters of echovirus 30 and enterovirus 71 and analysis of prevalent genotypes. J Med Virol 81, 317-324.

Palacios, G., Casas, I., Tenorio, A. \& Freire, C. (2002). Molecular identification of enterovirus by analyzing a partial VP1 genomic region with different methods. J Clin Microbiol 40, 182-192.

Pallansch, M. A. \& Oberste, M. S. (2003). Coxsackievirus, echovirus, and other enteroviruses. In Infectious Diseases, pp. 2047-2053. Edited by S. Gorbach, J. G. Bartlett \& N. R. Blacklow. Philadelphia, PA: Lippincott Williams \& Wilkins.

Pallansch, M. A. \& Roos, R. P. (2001). Enteroviruses: polioviruses, coxsackieviruses, echoviruses, and newer enteroviruses. In Fields Virology, 4th edn, pp. 723-775. Edited by D. M. Knipe, P. M. Howley, D. E. Griffin, R. A. Lamb, M. A. Martin, B. Roizman \& S. E. Straus. Philadelphia, PA: Lippincott Williams \& Wilkins.

Perevoscikovs, J., Lucenko, I. \& Nikiforova, R. (2006). Outbreak of enteroviral meningitis in Latvia, August-October 2006. Euro Surveill 11, E061005, 2.

Richter, J., Koptides, D., Tryfonos, C. \& Christodoulou, C. (2006). Molecular typing of enteroviruses associated with viral meningitis in Cyprus, 2000-2002. J Med Microbiol 55, 1035-1041.

Richter, J., Bashiardes, S., Koptides, D., Tryfonos, C., Pissarides, N., Stavrou, N., Papageorgiou, G. T. \& Christodoulou, C. (2008). 2005 poliovirus eradication: poliovirus presence in Cyprus 2 years after. Water Sci Technol 58, 647-651.

Rotbart, H. A. (1995). Meningitis and encephalitis. In Human Enterovirus Infections, pp. 271-289. Edited by H. A. Rotbart. Washington, DC: American Society for Microbiology.

Roth, B., Enders, M., Arents, A., Pfitzner, A. \& Terletskaia-Ladwig, E. (2007). Epidemiologic aspects and laboratory features of enterovirus infections in Western Germany, 2000-2005. J Med Virol 79, 956-962.
Santti, J., Hyypiä, T., Kinnunen, L. \& Salminen, M. (1999). Evidence of recombination among enteroviruses. J Virol 73, 8741-8749.

Simmonds, P. \& Welch, J. (2006). Frequency and dynamics of recombination within different species of human enteroviruses. J Virol 80, 483-493.

Stanway, G., Brown, F., Christian, P., Hovi, T., Hyypiä, T., King, A. M. Q., Knowles, N. J., Lemon, S. M., Minor, P. D. \& other authors (2005). Family Picornaviridae. In Virus Taxonomy: Eighth Report of the International Committee on Taxonomy of Viruses, pp. 757-778. Edited by C. M. Fauquet, M. A. Mayo, J. Maniloff, U. Desselberger \& L. A. Ball. London: Elsevier/Academic Press.

Tamura, K., Dudley, J., Nei, M. \& Kumar, S. (2007). MEGA4: Molecular Evolutionary Genetics Analysis (MEGA) software version 4.0. Mol Biol Evol 24, 1596-1599.

Tavakoli, N. P., Wang, H., Nattanmai, S., Dupuis, M., Fusco, H. \& Hull, R. (2008). Detection and typing of enteroviruses from CSF specimens from patients diagnosed with meningitis/encephalitis. J Clin Virol 43, 207211.

Thoelen, I., Lemey, P., Van Der Donck, I., Beuselinck, K., Lindberg, A. M. \& Van Ranst, M. (2003). Molecular typing and epidemiology of enteroviruses identified from an outbreak of aseptic meningitis in Belgium during the summer of 2000. J Med Virol 70, 420429.

Thoelen, I., Moës, E., Lemey, P., Mostmans, S., Wollants, E., Lindberg, A. M., Vandamme, A. M. \& Van Ranst, M. (2004). Analysis of the serotype and genotype correlation of VP1 and the 5' noncoding region in an epidemiological survey of the human enterovirus B species. J Clin Microbiol 42, 963-971.

Trallero, G., Avellon, A., Otero, A., De Miguel, T., Pérez, C., Rabella, N., Rubio, G., Echevarria, J. E. \& Cabrerizo, M. (2010). Enteroviruses in Spain over the decade 1998-2007: virological and epidemiological studies. J Clin Virol 47, 170-176.

Tsao, K. C., Huang, C. G., Huang, Y. L., Chen, F. C., Huang, P. N., Huang, Y. C., Lin, T. Y., Shih, S. R. \& Chang, S. C. (2010). Epidemiologic features and virus isolation of enteroviruses in Northern Taiwan during 2000-2008. J Virol Methods 165, 330-332.

WHO (2003). Guidelines for Environmental Surveillance of Poliovirus Circulation. Geneva: World Health Organization. 